\title{
Güvenli kalça dislokasyonu - femur başı prosedürleri
}

\author{
Safe dislocation - femoral head procedures
}

\author{
Ali Şeker ${ }^{1}$, illker Abdullah Sarıkaya² \\ 1İstanbul Medipol Üniversitesi Ortopedi ve Travmatoloji Anabilim Dalı \\ ${ }^{2}$ Çocuk Ortopedi Kliniği, Unimed Centre, İstanbul
}

\begin{abstract}
Güvenli femur başı dislokasyonu, femur başı patolojilerinin tedavisinde farklı amaçlarla kullanılabilir. Bu teknik, femoroasetabular sıkışma sendromunda uyumun sağlanması, kıkırdak sorunlarında rekonstrüksiyon, femur başı kırıklarının tedavisi, Perthes hastalığında oluşan deformitenin düzeltilmesi, femur başı epifiz kaymasının (FBEK) redüksiyonu ve femur başı yüzey artroplastisi sırasında kullanılabilmektedir. Komplikasyon oranları az olan bu yöntemle, ameliyat sırasında cerrahlara mükemmel bir görüş sağlanır.
\end{abstract}

Anahtar sözcükler: güvenli dislokasyon; femur başı; prosedür

\begin{abstract}
Several pathologies are treated with safe hip dislocation. Establishment of congruency in femoroacetabular impingement, reconstruction of chondral injuries, treatment of femoral head fractures, correction of Perthes disease sequela, reduction of slipped capitis femoral epiphysis, hip resurfacing arthroplasty can be performed by this technique. It has low complication rates and provides excellent exposure.
\end{abstract}

Key words: safe dislocation; femoral head; procedure üvenli femur başı dislokasyonu femur başı patolojilerinin tedavisinde farklı amaçlarla kullanılabilir. Bu yöntem, femoroasetabular sıkışma sendromunda uyumun sağlanması, kıkırdak sorunlarında rekonstrüksiyon, femur başı kırıklarının tedavisi, Perthes hastalığında oluşan deformitenin düzeltilmesi, femur başı epifiz kaymasının (FBEK) redüksiyonu, femur başı yüzey artroplastisi sırasında kullanılabilmektedir. Morbiditesi az olan bu işlem sonrası femur başı avasküler nekrozu ile karşılaşma ihtimali de azdır. Ameliyat sırasında cerrahlara mükemmel bir görüş sağlar. ${ }^{[1-4]}$ Bu bölümde, güvenli kalça dislokasyonu ile femur üst ucuna yönelik yapılabilen girişimler hakkında bilgi verilecektir.

\section{FEMUR BAŞI KIRIKLARI}

Femur başı kırıkları, sıklıkla travmatik kalça çıkıklarına eşlik edebilmektedir. Yüksek enerjili travmalar sonrası oluşan bu kırıklar, posterior kalça çıkığı olan hastaların \%7-16'sında görülür. ${ }^{[5,6]}$ Öne çıkıklarda ise bu oran \%15-77 arasında değişir. ${ }^{[7,8]}$ Acil redüksiyon gerektiren bu yaralanmanın tedavisinde öncelikli tedavi şekli, açık redüksiyon ve internal tespittir. Özellikle, eşlik eden femur boyun kırığı, redüksiyon sonrası kalça eklemleri arasında asimetrik görüntü, $2 \mathrm{~mm}$ 'den fazla ayrışma, ilerleyici siyatik sinir hasarı, eklem içi serbest parçalara bağlı kalça instabilitesi, açık redüksiyonun mutlak endikasyonları arasında sayılabilir. ${ }^{[2,5,9,10]}$ Klasik Smith-Petersen insizyonu ile, kalçaya önden yaklaşılıp ulaşılabilen bölgelere yönelik girişimler yapılabilir; ancak, bu yaklaşım çok sınırlı bir görüş sağlar. Güvenli kalça dislokasyonu ile mükemmel bir görüş alanı sağlanır ve kırığın anatomik redüksiyon kolaylaşır. Eklem içi serbest parçaların debridmanı, olası kalça instabilitesini ve kıkırdak hasarı oluşumunu önler. ${ }^{[6,9,10]}$

\section{FEMOROASETABULAR SIKIŞMA SENDROMU (FAS)}

Son dönemlerde sık görülen FAS, genç erişkinlerde kalça ağrısına yol açan önemli bir patolojidir; anormal gelişen femur üst ucu ve/veya asetabulumdan

- İletişim adresi: Yard. Doç. Dr. Ali Şeker, İstanbul Medipol Üniversitesi Ortopedi ve Travmatoloji Anabilim Dalı. TEM Avrupa Otoyolu Bağcılar Çıkışı No: 1, Bağcılar, İstanbul Tel: 0532 - 3262202 e-posta: aliseker@doctor.com

- Geliș tarihi: 23 Ocak $2015 \quad$ Kabul tarihi: 23 Ocak 2015 
kaynaklanır. Femur baş-boyun bileşkesi ile asetabulum kenarı arasında artan temasın, labrum ve kıkırdak hasarına, zamanla da kalça osteoartritine yol açtığı bilinmektedir. ${ }^{[11-13]}$ Cam-tipi FAS, femur baş-boyun bileşkesindeki konkavitenin yetersizliğinden kaynaklanır. Asetabulumla oluşan bu uyumsuzluk, Perthes hastalığı veya femur başı epifiz kayması (FBEK) gibi kalça sorunlarının komplikasyonu olarak oluşabileceği gibi, altta yatan bir neden de olmayabilir. ${ }^{[1,12]} \mathrm{Bu}$ sorunun tedavisinde, güvenli dislokasyon yaygın şekilde kullanılmaktadır. Bu işlem sırasında femur başboyun bileşkesi düzeltilir ve asetabulum ile olması gereken ilişki sağlanır. Osteokondroplasti olarak da adlandırılan bu işlem sırasında, osteotomlarla sıkışmaya neden olan bölümler çıkartılır ve femur başının sferikliği sağlanır. ${ }^{[1,14]}$

Sink ve arkadaşları, 71 adolesanda FAS nedeniyle uygulanan güvenli dislokasyon ile, işlevsel ölçeklerde anlamlı düzelme olduğunu vurgulamışlardır. ${ }^{[15]}$

Steppacher ve arkadaşları, 10 yıllık takibi olan 72 hastanın incelendiği çalışmalarında, hastaların \%80'inde klinik sonuçların iyi olduğunu ve radyografik olarak bozulma gözlenmediğini vurgulamışlardır. Yazarlar, başarısızlığın nedeni olarak, 40 yaş üstü olmayı, vücut kitle indeksinin $30 \mathrm{~kg} / \mathrm{m}^{2}$ üzerinde olmasını, lateral merkez kenar açısının $22^{\circ}$ 'nin altında veya $32^{\circ}$ 'nin üzerinde olmasını ve posterior asetabular örtümün \%34'ün altında olmasını bildirmişlerdir. ${ }^{[16]}$

Naal ve arkadaşları, FAS nedeniyle açık cerrahi yapılan ve cerrahi öncesi sportif faaliyetleri olan hastaların spora tekrar dönüşü sonrası, \%75'inin mevcut seviyelerinden memnun olduğunu, \%60,3'ünün performanslarının arttığını bildirmişlerdir. ${ }^{[17]}$

\section{FEMUR BAŞI EPIFIZ KAYMASI (FBEK)}

Güvenli kalça dislokasyonu, daha çok sekel olgularının tedavisinde kullanılmakla beraber, akut kaymaların redüksiyonunda da tercih edilebilir. ${ }^{[18,19]}$ Akut olgularda, kaymış epifiz olan pozisyonda, kalça Kirschner telleri ile geçici olarak tespit edildikten sonra disloke edilir. Teller çekilip epifiz redükte edildikten sonra, kalıcı tespit yapılır. Her ne kadar iyi sonuçlar bildirilse de, ${ }^{[12,20,21]}$ bu yöntemle avasküler nekroz oranlarının düşmediğini bildiren çalışmalar vardır. ${ }^{[22]}$

Kronik olgularda FAS gelişebildiğini daha önce belirtmiştik. Bu durumda, sekel tedavisi uygulanıp osteokondroplasti yapılabilir. Bunun yanında, subkapital osteotomi ile femur baş-boyun bileşkesi yeniden şekillendirilebilir. Kaynamama ve avasküler nekroz, subkapital osteotomi sonrası karşılaşılabilen komplikasyonlardandır. ${ }^{[23,24]}$

\section{PERTHES HASTALIĞI}

Perthes hastalığına bağlı femur üst ucu deformitesinde, güvenli dislokasyon ile femur başı yeniden şekillendirilip, gerekirse kıkırdak hasarına yönelik mozaikplasti ve kıkırdak debridmanı gibi işlemler yapılabilir (Şekil 1-4). ${ }^{[12]}$

Rebello ve arkadaşları, ileri deformitelerde güvenli dislokasyonun mükemmel bir görüş sağladığını ve nereden, ne kadar düzeltme yapılacağının başka bir yöntemle bu kadar iyi tespit edilemeyeceğini belirtmişlerdir. ${ }^{[25]}$ Benzer görüşü savunan Shin ve arkadaşları, günümüzde giderek popülerleşen kalça artroskopisinin, ileri olgularda güvenli dislokasyon kadar iyi görüş sağlayamayacağını vurgulamışlardır. ${ }^{[26]}$

Leunig ve Ganz, ileri deformitelerde başın güvenli dislokasyonu sonrası, femur boynuna göreceli uzatma ve femur başı küçülttme osteotomisi uygulamış ve en az üç yıllık takiplerinde hiç osteonekroz görülmediğini bildirmişlerdir. ${ }^{[27]}$

\section{FEMUR BAŞI KIKIRDAK SORUNLARI}

Femur başında çeşitli nedenlerle oluşmuş kıkırdak sorunları, güvenli kalça dislokasyonu ile tedavi edilebilir. Basit debridman, mikrokırık, mozaikplasti, otolog kondrosit implantasyonu veya kıkırdak dokusuna kılavuzluk edecek ajanların uygulanması sırasında, güvenli kalça dislokasyonu tercih edilebilir (Şekil 5-8).

Emre ve Girard, femur başında osteokondral veya sadece kıkırdak hasarı nedeniyle güvenli kalça dislokasyonu ve mozaikplasti yapılan hastalarının, erken dönem sonuçlarının iyi olduğunu vurgulamışlardır. ${ }^{[28,29]}$

\section{FEMUR BAŞı YÜZEY DEĞişTiRME ARTROPLASTISi}

Yakın geçmişe kadar sık kullanılan bu yöntem, daha sonra gelişen farklı komplikasyonlar nedeniyle, günümüzde daha az tercih edilmektedir. Sıklıkla kalçaya posterior yaklaşım tercih edilirken, güvenli kalça dislokasyonu da seçenekler arasındadır. ${ }^{[30]}$ 


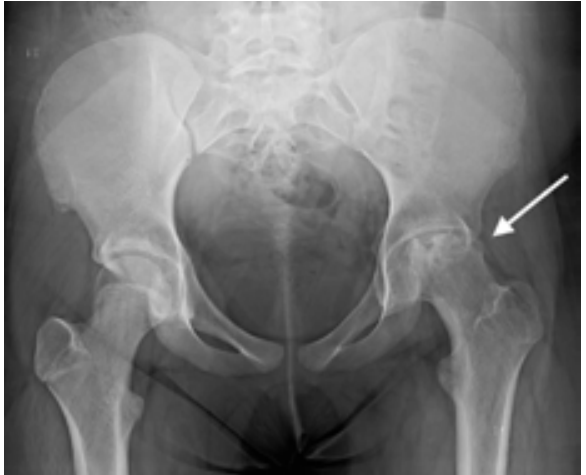

Şekil 1. Perthes hastalığı nedeniyle takipli hastada femur başının menteşe görevi gören bölümü (beyaz ok).

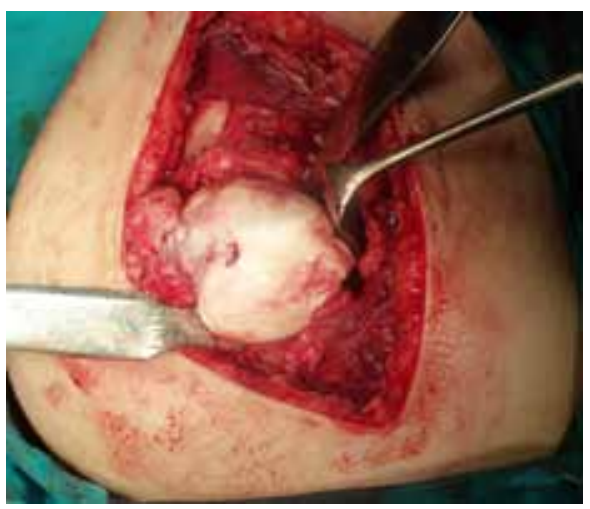

Şekil 2. Deforme femur başının ameliyat sırasındaki görüntüsü.

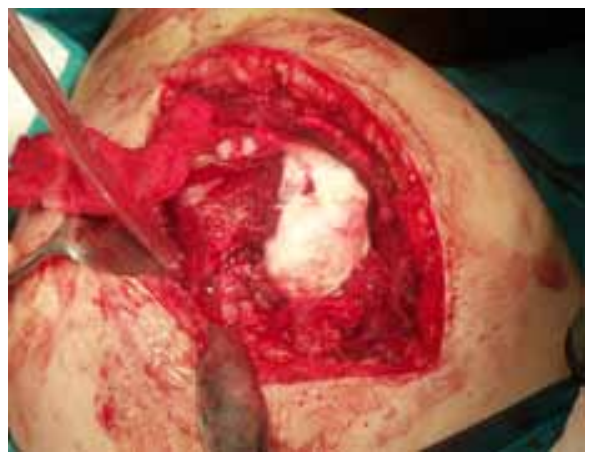

Şekil 3. Osteokondroplasti sonrası menteşe görevi gören bölüm çıkartıldı.

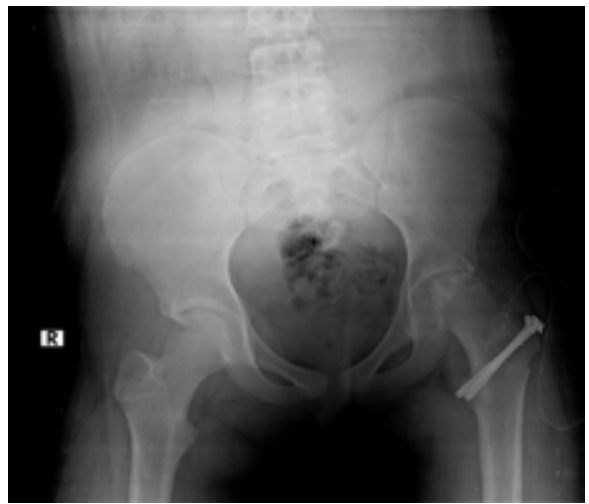

Şekil 4. Hastanın cerrahi sonrası pelvis grafısi.

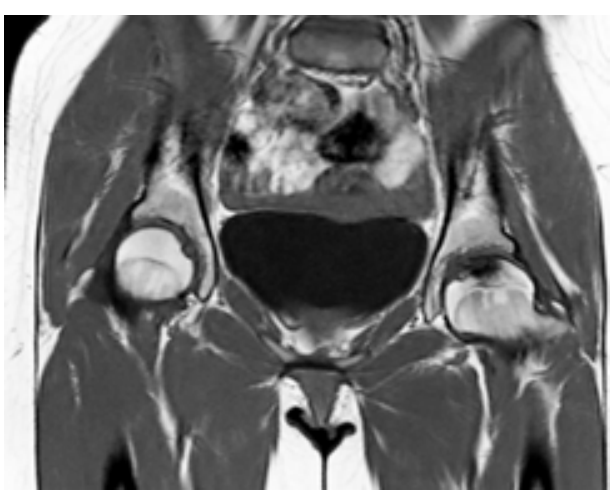

Şekil 5. On altı yaşında genç bir kızın sol femur başındaki nekrozu gösteren MR kesiti.

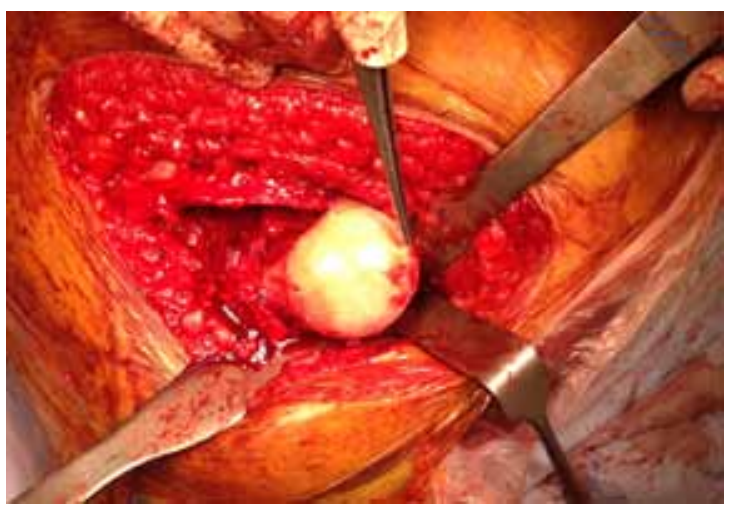

Şekil 6. Sağ|ıksız kıkırdağın görüntüsü.

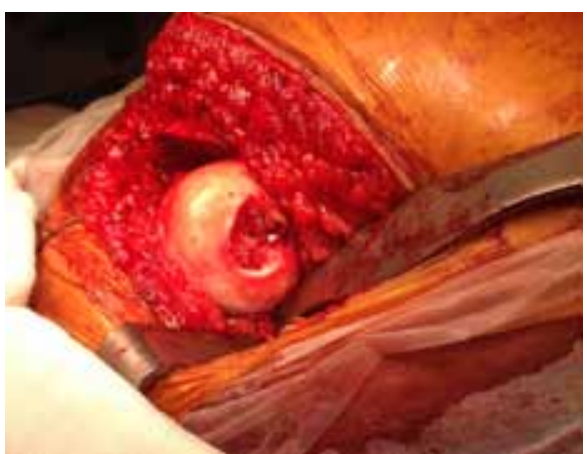

Şekil 7. Nekrotik kemik dokusu ve kıkırdağın debridmanı sonrası görüntü.

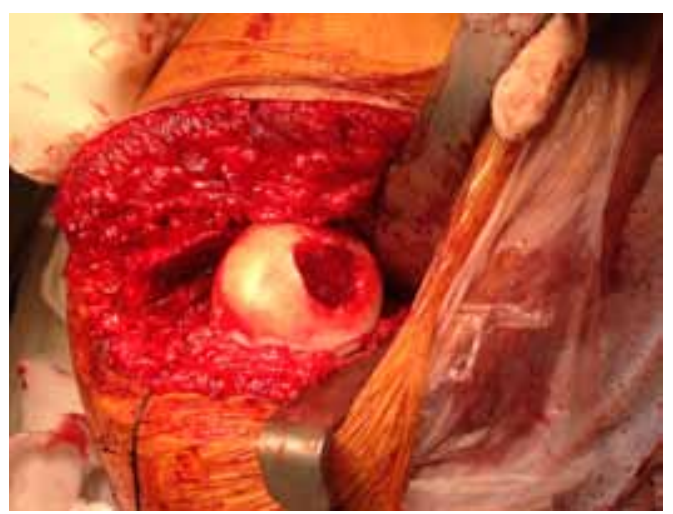

Şekil 8. Oluşan boşluğun kemik grefti ve üzerine kıkırdak doku kılavuzu ile doldurulmasını takiben son görüntü. 


\section{KAYNAKLAR}

1. Ganz R, Gill TJ, Gautier E, Ganz K, Krügel N, Berlemann U. Surgical dislocation of the adult hip a technique with full access to the femoral head and acetabulum without the risk of avascular necrosis. J Bone Joint Surg 2001;83(8):1119-24.

2. Siebenrock KA, Gautier E, Woo AK, Ganz R. Surgical dislocation of the femoral head for joint debridement and accurate reduction of fractures of the acetabulum. J Orthop Trauma 2002;16(8):543-52.

3. Schachter AK, Lamont JG. Surface replacement arthroplasty of the hip. Bull NYU Hosp Jt Dis 2009;67(1):75-82.

4. Beaulé PE, Shim P, Banga K. Clinical experience of Ganz surgical dislocation approach for metal-on-metal hip resurfacing. J Arthroplasty 2009;24(6 Suppl):127-31. CrossRef

5. Mostafa MM. Femoral head fractures. Int Orthop 2001;25(1):51-4.

6. Sahin V, Karakaş ES, Aksu S, Atlihan D, Turk CY, Halici M. Traumatic dislocation and fracture-dislocation of the hip: a long-term follow-up study. J Trauma 2003;54(3):520-9.

7. DeLee JC, Evans JA, Thomas J. Anterior dislocation of the hip and associated femoral-head fractures. J Bone Joint Surg 1980;62(6):960-4.

8. Epstein HC, Harvey JP Jr. Traumatic anterior dislocations of the hip: management and results. An analysis of fifty-five cases. J Bone Joint Surg Am 1972;54:1561-2.

9. Swiontkowski MF. Intracapsular hip fractures. In: Browner BD, editor. Skeletal Trauma: Basic Science, Management, and Reconstruction, 4th ed. Philadelphia: Saunders/Elsevier; 2009. p.1833-914.

10. Koval KJ, Kregor PJ. Hip dislocation and femoral head fractures. In: Berry DJ, Liebermann JR, editors. Surgery of the Hip. Saunders Elsevier; 2013. p.614-29.

11. Ganz R, Parvizi J, Beck M, Leunig M, Nötzli H, Siebenrock KA. Femoroacetabular impingement: a cause for osteoarthritis of the hip. Clin Orthop Relat Res 2003;(417):112-20.

12. Ross JR, Schoenecker PL, Clohisy JC. Surgical dislocation of the hip: evolving indications. HSS J 2013;9(1):60-9. CrossRef

13. Beck $M$, Kalhor $M$, Leunig $M$, Ganz R. Hip morphology influences the pattern of damage to the acetabular cartilage: femoroacetabular impingement as a cause of early osteoarthritis of the hip. J Bone Joint Surg Br 2005;87(7):1012-8.

14. Beck M, Leunig M, Parvizi J, Boutier V, Wyss D, Ganz R. Anterior femoroacetabular impingement: part II. Midterm results of surgical treatment. Clin Orthop Relat Res 2004;(418):67-73.

15. Sink EL, Fabricant PD, Pan Z, Dayton MR, Novais E. Results of treatment of femoroacetabular impingement in adolescents with a surgical hip dislocation approach. Clin Orthop Relat Res 2013;471(8):2563-9. CrossRef

16. Steppacher SD, Anwander H, Zurmühle CA, Tannast M, Siebenrock KA. Eighty Percent of Patients With Surgical Hip Dislocation for Femoroacetabular Impingement Have a Good Clinical Result Without Osteoarthritis Progression at 10 Years. Clin Orthop Relat Res 2014. [Epub ahead of print]
17. Naal FD, Schär M, Miozzari HH, Nötzli HP. Sports and Activity Levels After Open Surgical Treatment of Femoroacetabular Impingement. Am J Sports Med 2014;42(7):1690-5.

18. Slongo T, Kakaty D, Krause F, Ziebarth K. Treatment of slipped capital femoral epiphysis with a modified Dunn procedure. J Bone Joint Surg Am 2010;92(18):2898-908. CrossRef

19. Ziebarth K, Zilkens C, Spencer S, Leunig M, Ganz R, Kim YJ. Capital realignment for moderate and severe SCFE using a modified Dunn procedure. Clin Orthop Relat Res 2009;467(3):704-16. CrossRef

20. Madan SS, Cooper AP, Davies AG, Fernandes JA. The treatment of severe slipped capital femoral epiphysis via the Ganz surgical dislocation and anatomical reduction: a prospective study. Bone Joint J 2013;95-B(3):424-9. CrossRef

21. Shin SJ, Kwak HS, Cho TJ, Park MS, Yoo WJ, Chung CY, Choi $\mathrm{IH}$. Application of Ganz surgical hip dislocation approach in pediatric hip diseases. Clin Orthop Surg 2009;1(3):132-7. CrossRef

22. Alves C, Steele M, Narayanan U, Howard A, Alman B, Wright JG. Open reduction and internal fixation of unstable slipped capital femoral epiphysis by means of surgical dislocation does not decrease the rate of avascular necrosis: a preliminary study. J Child Orthop 2012;6(4):277-83. CrossRef

23. Anderson LA, Gililland JM, Pelt CE, Peters CL. Subcapital correction osteotomy for malunited slipped capital femoral epiphysis. J Pediatr Orthop 2013;33(4):345-52. CrossRef

24. Bali K, Railton P, Kiefer GN, Powell JN. Subcapital osteotomy of the femoral neck for patients with healed slipped capital femoral epiphysis. Bone Joint J 2014;96-B(11):1441-8. CrossRef

25. Rebello G, Spencer S, Millis MB, Kim YJ. Surgical dislocation in the management of pediatric and adolescent hip deformity. Clin Orthop Relat Res 2009;467(3):724-31. CrossRef

26. Shin SJ, Kwak HS, Cho TJ, Park MS, Yoo WJ, Chung CY, Choi $\mathrm{IH}$. Application of Ganz surgical hip dislocation approach in pediatric hip diseases. Clin Orthop Surg 2009;1(3):132-7. CrossRef

27. Leunig M, Ganz R. Relative neck lengthening and intracapital osteotomy for severe Perthes and Perthes-like deformities. Bull NYU Hosp Jt Dis 2011;69 Suppl 1:S62-7.

28. Emre TY, Cift H, Seyhan B, Ceyhan E, Uzun M. Mosaicplasty for the treatment of the osteochondral lesion in the femoral head. Bull NYU Hosp Jt Dis 2012;70(4):288-90.

29. Girard J, Roumazeille T, Sakr M, Migaud H. Osteochondral mosaicplasty of the femoral head. Hip Int 2011;21(5):542-8. CrossRef

30. Schachter AK, Lamont JG. Surface replacement arthroplasty of the hip. Bull NYU Hosp Jt Dis 2009;67(1):75-82. 